\title{
Innovative approach to the problem of preventing the formation of icing on the roofs of buildings in the spring and winter
}

\author{
Nikolay Khlobystin, Anastasia Kingasheva* and Dmitry Brenchaninov \\ Peter the Great St. Petersburg Polytechnic University, Saint Petersburg, 195251, Russia
}

\begin{abstract}
Only during 2010 - 2019 more than 100 people have suffered from falling of icicles from roofs. In most cases people get slight injuries, but sometimes it reaches lethal outcome. Also damage is sustained by cars, pavements, shops that are in commercial rooms on the first floors of houses, etc. In the conditions of continuous modernization of design of houses, construction companies do not resolve the matter. In this article the problem of formation of frost during the spring and winter period is studied. We have assessed the probabilities of suffering damage from icicles falling from various heights. The innovative device that does not have analogy around the world and eliminates defects of already existing patents is presented.
\end{abstract}

\section{Introduction}

The relevance of safety of people during the spring and winter period is confirmed by a set of the facts from which main thing is preservation of human life. But in the presence in the world more than 750 patents, including over 300 of Russia, this problem so fully is also not solved.

Object of a research is the way of fight against frost (icicles).

The work purpose - development of recommendations and practical offers on decrease in danger of this type in city conditions during spring and winter snowmelt on the basis of schedules of probability of defeat of the population frost (icicles) from roofs.

Probability of defeat of the person can change in connection with different conditions, for example weather, also depends on material of a roof of a roof on which frost, distances of passing of the person from a dangerous zone, etc. was formed. Unfortunately, the experiment by training of icicles on different materials of a roof cannot be executed due to the lack of the due equipment. Also, there are no maximum permissible values for calculation of the striking icicle phenomenon on the person enshrined in the order or the law that assumes lack of an opportunity to calculate with what probability the icicle will fall to the person under these or those circumstances.

Thus, we can calculate only theoretically the probability of defeat of the person an icicle, using the speed of falling of an icicle as extreme values.

\section{Methods}

\subsection{Initial data}

Let's consider that height of one floor of a house is approximately equal 3 meters, then height of the 3-storey house about 9 meters, height of the 5-storey house of 15 meters and height of the 9-storey house of 27 meters respectively.

By means of a formula (1), for finding of speed in free fall, we can calculate the speed of falling of an icicle at different values of height

$V=(2 g h)^{\frac{1}{2}}$,

where V - falling speed in $\mathrm{m} / \mathrm{s}$; g - acceleration of gravity, $9.81 \mathrm{~m} / \mathrm{s}^{2} ; \mathrm{h}-$ height from which the body in $\mathrm{m}$ falls.

So when falling an icicle from the 3-storey house speed $V_{1}=13,2 \mathrm{~m} / \mathrm{s}$, from height of the 5-storey house of $V_{2}=17,15 \mathrm{~m} / \mathrm{s}$, and from 9-storey $V_{3}=23,01 \mathrm{~m} / \mathrm{s}$.

Let's take the speed of falling of an icicle from height of one floor for the safe speed of $V_{b}=7,7 \mathrm{~m} / \mathrm{s}$. For determination of speed of defeat at which the death of the person will occur we will take average value from speeds of $V_{1}, V_{2}$ and $V_{3}$ and then $V_{p}=17,9 \mathrm{~m} / \mathrm{s}$ is the speed at which there is a lethal outcome.

\subsection{The used formulas}

The probability of occurrence of at least one of the events A1, A2 ... An independent in the aggregate is equal to

\footnotetext{
*Corresponding author: akingasheva@bk.ru
} 
$P(A)=1-P\left(\overline{A_{1}}\right) \times P\left(\overline{A_{2}}\right) \times \ldots \times P\left(\overline{A_{n}}\right)$,

where event $\mathrm{A}=$ \{the occurrence of at least one of the events $A_{1}, A_{2} \ldots A_{n}$, denoting $P\left(\overline{A_{1}}\right)=q_{1}, P\left(\overline{A_{2}}\right)=$ $\mathrm{q}_{2} \ldots$ we get

$$
\begin{aligned}
& P(A)=1-q_{1} \times q_{2} \cdot \ldots \cdot q_{n}, \\
& \quad \text { If } \mathrm{q}_{1}=\mathrm{q}_{2}=\cdots \mathrm{q}_{\mathrm{n}} \text {, then } \\
& P(A)=1-q_{n},
\end{aligned}
$$

Using a formula for probability that at least one case will occur, we will construct a series of schedules for different streets of St. Petersburg where 3-storey, 5storey and 9-storey houses are presented.

Coefficients which we take into account it is coefficients of probability of falling of ice on the head and on a trunk, taken from the manual by Hramov G.N. [1].

Probability of falling of frost on the head of the person is much higher, than falling of frost on a trunk, from this it follows that at calculation of probability of falling of frost either on a trunk or on the head fairly this expression:

$$
P=P_{h} \times 0.7+P_{t} \times 0.3
$$

\section{Results}

On the street where 3-storey house sare presented, height of the house is $\mathrm{h} 1=9 \mathrm{~m}$, from here the speed of $\mathrm{V} 1=$ $13,2 \mathrm{~m} / \mathrm{s}$. At once we pay attention that the speed of falling of an icicle is less than the speed of defeat, from this it follows that when falling an icicle from the 3storey house of people will be traumatized, but will survive.

For creation of the schedule we will set a speed interval from $5 \mathrm{~m} / \mathrm{s}$ to $30 \mathrm{~m} / \mathrm{s}$ with a step 0.5 . On schedule (fig. 1) it is visible that the continuous line of red color - the probability of falling of frost on the head. The line a dot-dash line of blue color - the probability of falling of frost on a trunk, and a dashed line of green color - the probability of falling of frost on the head or on a trunk.

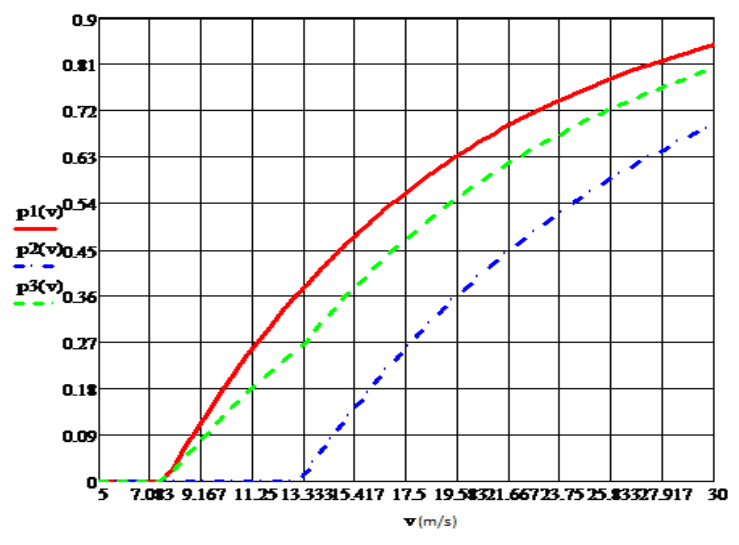

Fig. 1.Schedule of probability of defeat at $h=9 m$.

Further, we build the schedule for 5-storey houses, with $\mathrm{h}=15 \mathrm{~m}$ height, the speed of $\mathrm{V}=17.15 \mathrm{~m} / \mathrm{s}$ from here, we also note the fact that, as well as in the previous option, falling of an icicle will not lead to a lethal outcome.

But, in comparison with the previous speed, in this option, the person can suffer very serious injuries which can leave him the disabled person for the rest of life.

For creation of the schedule we will set a speed interval from $5 \mathrm{~m} / \mathrm{s}$ to $30 \mathrm{~m} / \mathrm{s}$ with a step 0.5 . From the schedule it is visible (fig. 2), a trend of increase in probability of defeat of the person frost from a roof.

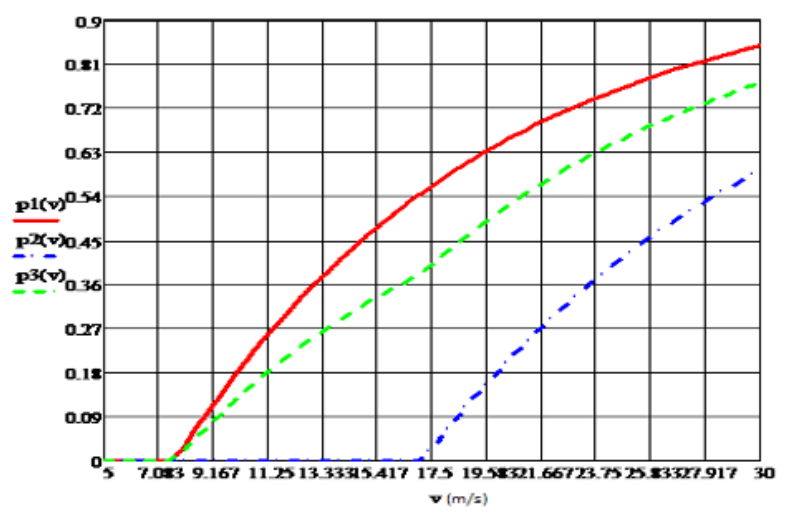

Fig. 2.Schedule of probability of defeat at $\mathrm{h}=15 \mathrm{~m}$.

Let's construct the schedule for the 9-storey house where $\mathrm{h}=27 \mathrm{~m}$, and $\mathrm{V}=23.01 \mathrm{~m} / \mathrm{s}$ page speed. In this case we see that the speed which is gathered by an icicle is much more defeat speed, a conclusion follows from here that when falling an icicle on the person from height of the 9-storey house - the person will not survive.

For creation of the schedule of dependence of probability on speed we will set a speed interval from 5 $\mathrm{m} / \mathrm{s}$ to $30 \mathrm{~m} / \mathrm{s}$ with a step 0.5 . According to the schedule it is visible (fig. 3) that defeat probability frost decreases by a trunk of the person. 


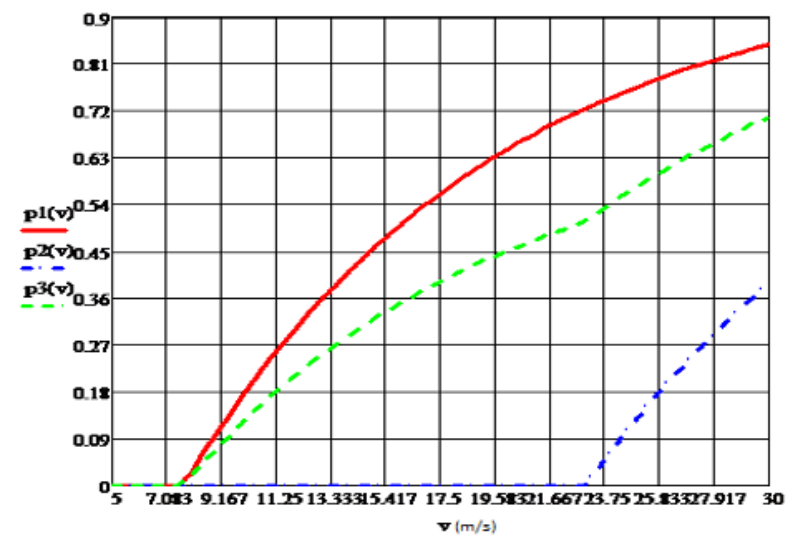

Fig. 3.Schedule of probability of defeat at $h=27 \mathrm{~m}$.

The analysis of the carried-out calculations shows that at increase in height of falling of frost, the probability of defeat of the person increases.

It is impossible to forget also that the volume and mass of the falling frost is an important factor when calculating of the striking probability as when falling a big block of ice even from height of the 5-storey house there is a probability of a lethal outcome. Accounting of these factors is of interest when carrying out researches on this problem [2].

\subsection{Engineering of an innovative device. Description}

The Antiled device which was offered by Khlobystin Nikolay Semyonovich, answers much of the set conditions. The sense is that the device works at the expense of the weight of icicles which begin to be formed during the spring and winter period. From here costs of service of roofs, their repair are reduced, and the risk of getting injured by the pedestrians and people removing roofs is also minimized.

\subsection{Principle of action}

The offered device cardinally differs from already existing inventions in what does not use the electric power, and uses energy of growth of the formed icicles. In fig. 4 the general scheme of this device is submitted. Icicles which are formed on an edge of a roof "grow" under the influence of terrestrial gravitation down. In parallel icicles "grow" and on the blade of "roller" acting from under a roof on several millimeters which having reached a certain volume (critical weight) influence the weight the device blade, setting "roller" in rotary motion. The subsequent to it the blade, reaching icicles on the edge of a roof, forces down them, and the icicles formed on the blade are broken off under the influence of a body weight. Thereby there is a destruction of icicles at a stage of their growth, still small, that is before emergence of "giant icicles" [3].

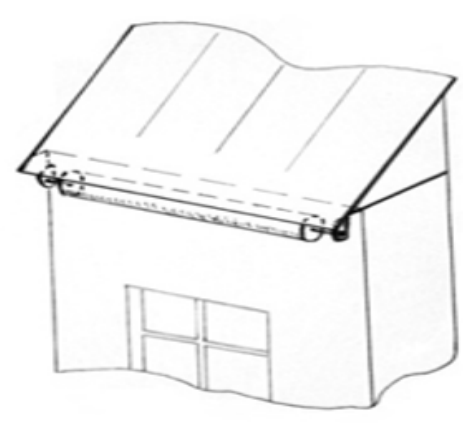

Fig. 4.Schematically image of the innovative device.

Basic elements of the device include:

- an arm eaves - 2 pieces;

- "roller" subeaves with blades.

The different composition of material of which the device that will prevent sticking of frost to blades is manufactured is necessary for different meteoconditions [4]. Use of the special coverings applied to decrease in extent of sticking of ice to various materials i.e. adhesions is possible [5].

Icicles, affecting with the weight the device, set it in motion, blades have to be scrolled exactly on one position. The blade which gravity affected is turned down. The blade following it, moving ahead, strikes the icicles formed on eaves, cutting off them. That the device did not turn as "revolving object", and carried out a step-by-step cycle of work, use of the spring clamp presented in fig. 5 is necessary [6].
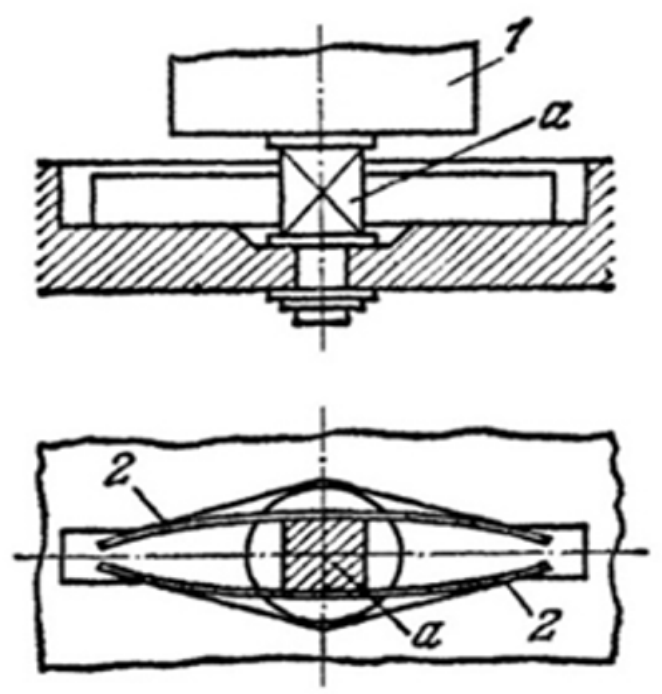

Fig. 5.Spring clamp. (1-roller, 2-flat springs, a-the square on a roller axis).

\section{Discussion}

Schedules of probability of defeat of the person on which it is visible that with a height about the 5-storey house above, the person can suffer serious injuries not compatible to life are presented. It is relevant for the city of St. Petersburg as housing stock generally consists of houses with five floors. Calculations were conducted on 
an emergence probability formula at least of one event. Coefficients are taken for defeat of the person on the head, or in a trunk that gives the chance to consider different scenarios. It is possible to determine height with which falling of frost on the person, will be deadly by schedules. But, unfortunately experimental calculations in this area were not carried out yet, so, all factors, for example as the volume and mass of the falling frost are not considered. In this regard it is possible to assume with confidence that if frost reaches the "huge" sizes, defeat height, maybe, to decrease twice, and even three times.

And innovative approach to a solution, prevention of formation of icicles is also presented. It is possible to install this Antiled device under roofs of different types and the sizes. Its work does not demand constant service by the person, there are no electric power expenses that has to become attractive to UK in the economic plan. Final implementation of this project requires carrying out further calculations and completions in questions of the put covering, determination of the sizes and the number of blades of the roller and also distances at which they have to be established from the roof edge.

\section{References}

1. G. N. Hramov Technogenic explosions: studies. grant / G.N. Hramov; St. Petersburg state polytechnical university. — SPb., (2007).

2. The article "The death of a woman from falling icicles" [Electronic Resource]. - URL: https://www.saratovnews.ru/news/2019/02/27/gibel -jenschiny-ot-padeniya-sosylki-vozbyjdenoygolovnoe-delo

3. N.S. Khlobystin, D.A. Galkin, Innovative approach to the problem of preventing the formation of ice (icicles) on the roofs of buildings / Collection of scientific papers of the Xth All-Russian ScientificPractical Conference "Safety in Emergency Situations". - SPb .: Polytechnic Publishing House. (2018).

4. S.A. Sokolov, A.A. Grachev. Local criterion for strength of elements of steelwork International Review of Mechanical Engineering, (2018).

5. Khlobystin N.S., Tumanov A.Yu. Business plan of the innovation project. The device and method of protection from ice overhangs of roofs in St. Petersburg, Publishing house SPbGPU, (2011).

6. Khlobystin N.S. A device and a method of protection against ice overhangs of roofs Rostovon-Don / D: Don State Technical University,(2017).

7. , J.C. Yde, J.D. Žárský, T.J. Kohler, N.T. Knudsen, M.K. Gillespie, M. Stibal, Kuannersuit Glacier revisited: Constraining ice dynamics, landform formations and glaciomorphological changes in the early quiescent phase following the 1995-98 surge event. Geomorphology, (2019).

8. M. Dement'eva, Factors of quality reduction of exploitation of pitched roofs with a cold attic in conditions of dense urban development. MATEC Web of Conferences, 02019 (2017) .
9. M.R. Petrichenko, D.V. Nemova, D.S. Tarasova, A.A. Staritcyna, The double-layernonstationaryheat conduction. Measures to prevent the formation icedamson the roof, Materials Science \& Engineering, 580, 2308 (2014).

10. A. Ustinov, O. Zybina, L. Tanklevsky, V. Lebedev, A. Andreev, Intumescent coatings with improved properties for high-rise construction (2018) E3S Web of Conferences, 33, paper № 02039

11. Mohammed, A.H., Al-zuwaini, H., Sergeev, V., Socolova, E., Skulkin, S., Mukhametova, L., International Journal of Mechanical Engineering and Technology, pp. 1375-1390. (2019) 